\title{
Public transport travel time perception: effects of socioeconomic characteristics, trip characteristics and facility usage
}

Meng Meng ${ }^{1 *}$, Andreas Rau ${ }^{1}$, Hita Mahardhika ${ }^{1}$

1. TUM Create, 1 Create Way, \#10-02 Create Tower, Singapore 138602, Singapore

* Corresponding author: Meng Meng, Telephone: (65) 6601 4015, Email: meng.meng@tum-create.edu.sg

\begin{abstract}
Perceived travel time in public transport trip directly affects passengers' satisfaction and therefore is an essential consideration when planning and operating the public transport system. However, beyond the prevalent analysis on the waiting time perception, there are few articles that have concerned the travel time perception along the entire multimodal trip. In this context, this paper presents an empirical investigation of actual and perceived travel time at each stage in a bus-rail transport trip, where first mile, in-vehicle stage, transfer stage and last mile are all considered. Data on actual and perceived travel time, socioeconomic characteristics, trip characteristics and facility usage are collected by accompany survey undertaken from passengers' originations to destinations. The results from a series of paired T-tests show that passenger do perceive travel time to be greater than the actual amount at each stage. Three linear regression models are developed for estimation of perceived walking, waiting and in-vehicle time. Results indicate that socioeconomic characteristics, trip characteristics and facility usage seem to have an impact on passengers' travel time perception, while the travel time spent on the previous stage does not affect the perception too much.
\end{abstract}

Key words: Public transport; travel time perception; socioeconomic characteristics; trip characteristics; facility usage 


\section{Introduction}

Travel time is one of the core elements that heavily affect the passengers' opinions on the quality of public transport service (Krygsman et al., 2004). Nowadays, passengers often use more than one traffic mode or service to complete the trip. Accordingly, the total travel time includes all supplementary travel times between the origin and destination such as wait time, walking time etc. An example is shown in Figure 1, where passenger first walks from his/her home to the bus station, then takes one bus to a Massive Rapid Transit (MRT) station, after that walks to the office at last. This trip contains three traffic modes, walk, bus and MRT, with five trip stages, first mile, first main haul (bus), transfer stage, second main haul (MRT), and last mile. Correspondingly, the travel time in this trip includes out-of-vehicle time and in-vehicle time, where out-of-vehicle time contains walking time and waiting time.

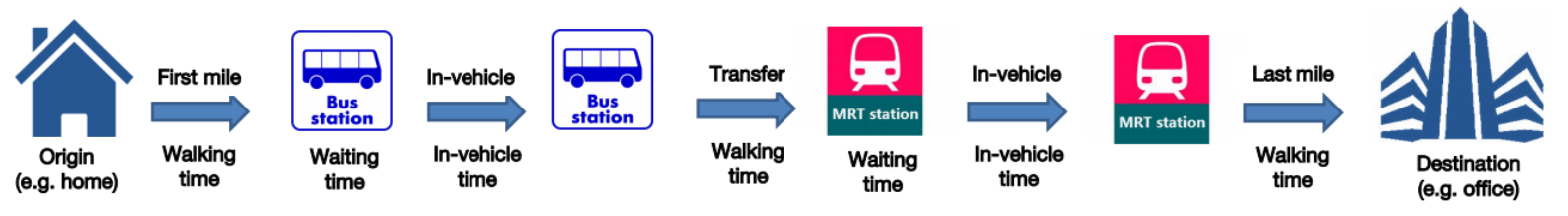

Figure 1 Trip stages and travel time in a multimodal public transport trip

Studies have found that passengers may not perceive the travel time accurately due to various factors (Hess et al. 2004; Psarros et al. 2011; Dewulf et al., 2012). Take waiting time at public transport station as an example, passengers generally expect to get on the bus as soon as possible. Being exposed to lack of comfort, crowding, and poor weather condition, passengers often perceived waiting longer than they actually spend (Beirão and Cabral, 2007). Therefore, it is more reasonable to use passengers' perceived travel time instead of actual travel time in traffic planning and operation. Currently, to our best of knowledge, existing studies on the travel time perception issue all focus on one particular trip stage and none of them has investigated the travel time perception on the basis of a complete trip (Diab et al., 2015; Meng et al., 2016). Meanwhile, most of studies put the attention on the influence of passengers' socioeconomic characteristics and trip characteristics on the travel time perception, while the influence of facility usage and the effect from the previous trip stage have not been explored clearly. 
Based on the afore-mentioned concerns, the objective of this paper is to check the differences between perceived and actual travel time in a multimodal trip, and then model and quantify the perceived travel time through linear regression model. To achieve these objectives, three questions need to be discussed through the analysis from filed survey, which are: firstly, are there always perception differences for all travel time components; secondly, what factors influence the perception; thirdly, how to quantify the perceived travel time. Having established the study's motivation, the rest of the paper is structured as followed: the next section provides a brief background of past works on travel time perception. Then, a description of our methodology and presumption is given, followed by the models and results. Findings are summarised at last. The outcomes of this paper could provide foundation for other modellers and traffic plannersespecially when considering multi-modal mode choice situation in public transport system.

\section{Literature Review}

Travel time perception has been a hot topic of interest in public transport field as the rising importance of passenger satisfaction. Actual travel time is the clock time difference between the departure and arrival. Perceived travel time is the duration that the passenger felt that he/she was spending between the departure and arrival. Generally, the perceived travel time could be either greater or lesser than the actual travel time due to various reasons. One of the classical findings on time perception by Vierordt (1868) was that short activities were usually overestimated while long activities were usually underestimated. Many similar studies were conducted on the topic of time perception (Yarmey, 2000; Block and Gruber, 2014), in which the studies on travel time perception have made extraordinary progress. Table 1 listed most of the represented studies on travel time perception in recent years. 


\begin{tabular}{|c|c|c|c|c|c|c|}
\hline Author \& year & Study item & City & $\begin{array}{l}\text { Sample } \\
\text { size }\end{array}$ & $\begin{array}{l}\text { Survey } \\
\text { method }\end{array}$ & Results & Influence factors \\
\hline Yarmey, 2000 & Waiting time & Guelph, Canada & 1015 & $\begin{array}{l}\text { Laboratory } \\
\text { experiments }\end{array}$ & $\begin{array}{l}\text { Repeated experience could help } \\
\text { traveller to correctly estimate the } \\
\text { waiting time. }\end{array}$ & Travel experience \\
\hline Hall, 2001 & Waiting time & $\begin{array}{l}\text { Los Angeles, } \\
\text { USA }\end{array}$ & 1199 & Field survey & $\begin{array}{l}\text { Passengers who have the knowledge } \\
\text { of the schedule perceived waiting } 3.57 \\
\text { min less than passengers who don't } \\
\text { have the knowledge. }\end{array}$ & $\begin{array}{l}\text { Age, language groups and trip } \\
\text { types }\end{array}$ \\
\hline Hess et al. 2004 & Waiting time & $\begin{array}{l}\text { Los Angeles, } \\
\text { USA }\end{array}$ & N.A. & Field survey & $\begin{array}{l}\text { Passengers perceived that they spend } \\
5.3 \text { min more than the actual waiting } \\
\text { time, and the standard deviation of } \\
\text { additional wait time was } 3.3 \text { min. }\end{array}$ & N.A. \\
\hline $\begin{array}{l}\text { Walle and } \\
\text { Steenberghen, } \\
2006\end{array}$ & $\begin{array}{l}\text { Walking time, } \\
\text { waiting time }\end{array}$ & Belgium & $\begin{array}{l}\text { About } \\
7,000\end{array}$ & $\begin{array}{l}\text { Nation-wide } \\
\text { mobility } \\
\text { survey }\end{array}$ & $\begin{array}{l}\text { Perceived waiting and walking time } \\
\text { will affect the public transport usage. }\end{array}$ & N.A \\
\hline $\begin{array}{l}\text { Mishalani et al., } \\
2006\end{array}$ & Waiting time & Columbus, USA & 83 & Field survey & $\begin{array}{l}\text { The average overestimation of waiting } \\
\text { time is } 0.84 \mathrm{~min} .\end{array}$ & $\begin{array}{l}\text { Actual waiting time, walking } \\
\text { time before waiting }\end{array}$ \\
\hline $\begin{array}{l}\text { Beirão and } \\
\text { Cabral, } 2007\end{array}$ & Waiting time & Porto, Portugal & 24 & $\begin{array}{l}\text { Qualitative } \\
\text { method }\end{array}$ & $\begin{array}{l}\text { Waiting time is perceived as too long, } \\
\text { which is a barrier to public transport } \\
\text { use }\end{array}$ & N.A. \\
\hline $\begin{array}{l}\text { Daskalakis and } \\
\text { Stathopoulos, }\end{array}$ & Waiting time & Athens, Greece & 300 & Field survey & $\begin{array}{l}\text { Passengers perceive waiting time } \\
\text { differently from the actual time }\end{array}$ & N.A. \\
\hline
\end{tabular}




\begin{tabular}{|c|c|c|c|c|}
\hline $\begin{array}{l}\text { Fan and } \\
\text { Machemehl, } 2009\end{array}$ & Waiting time & Texas, USA & $\begin{array}{l}\text { 6-month } \\
\text { period }\end{array}$ & $\begin{array}{l}\text { Direct } \\
\text { observation }\end{array}$ \\
\hline $\begin{array}{l}\text { Psarros et al. } \\
2011\end{array}$ & Waiting time & Athens, Greece & $\begin{array}{l}\text { Over } \\
1,000\end{array}$ & Field survey \\
\hline $\begin{array}{l}\text { Watkins et al., } \\
2011\end{array}$ & Waiting time & $\begin{array}{l}\text { Washington } \\
\text { D.C., USA }\end{array}$ & 655 & Field survey \\
\hline
\end{tabular}

Yoh et al., $2011 \quad$ Waiting time Colifornia, USA $\quad 2,247 \quad$ Field survey

Dewulf 2012 for reasons such as being exposed to adverse weather conditions, the surrounding environment,

and the experience of being stressed by waiting anxiety

An 11-min vehicle headway was Bus line headway identified to mark the transition from practically random to less random passenger arrivals.

The ratio of average perceived to Actual waiting time, age, trip average actual waiting time is in a purpose, trip time period. range varies from 1.35 to 2.03 according to time period, gender, age groups and trip purposes.

Passengers using traditional arrival Availability of real-time information perceive that they are information, peak period, waiting $0.83 \mathrm{~min}(15 \%)$ longer .than buses per hour, aggravation they are, while passengers using level.

real-time arrival information perceive more accurate.

Waiting time was paramount to Lighting, cleanliness, passengers through more than 2000 information, shelter, and the passenger surveys. Influence factors presence of guards. varied for different waiting time.

Low-level walkers tended to Physical activity, overestimate walking time neighbourhood walkability, and socio-demographic characteristics. 


\begin{tabular}{|c|c|c|c|c|c|c|}
\hline $\begin{array}{l}\text { Millonig and } \\
\text { Sleszynski, } 2012\end{array}$ & Waiting time & $\begin{array}{l}\text { Innsbruck, } \\
\text { Wiener Neustadt } \\
\text { and Linz, } \\
\text { Austria }\end{array}$ & 1,215 & Field survey & $\begin{array}{l}\text { With increasing time spent on the } \\
\text { station, people generally tend to } \\
\text { stronger underestimate the waiting } \\
\text { time. }\end{array}$ & $\begin{array}{l}\text { Station characteristics and } \\
\text { user characteristics }\end{array}$ \\
\hline $\begin{array}{l}\text { Parthasarathi et } \\
\text { al., } 2013\end{array}$ & Waiting time & $\begin{array}{l}\text { The Twin Cities, } \\
\text { USA }\end{array}$ & 273 & Field survey & $\begin{array}{l}\text { Network design influences passengers' } \\
\text { perceptions, more specifically the } \\
\text { perceptions of distance/travel time. }\end{array}$ & $\begin{array}{l}\text { Network design, like relative } \\
\text { discontinuity, P2A (Perimeter } \\
\text { to Area), Street density, } \\
\text { Intersection density. }\end{array}$ \\
\hline $\begin{array}{l}\text { Cheng and Tsai, } \\
2014\end{array}$ & Waiting time & Taiwan & 992 & Field survey & $\begin{array}{l}\text { Certain scenarios can reduce certain } \\
\text { passengers' perceived waiting time in } \\
\text { the case of a train delay. }\end{array}$ & $\begin{array}{l}\text { Age, gender, educational } \\
\text { level, monthly income, and } \\
\text { train-riding frequency. }\end{array}$ \\
\hline $\begin{array}{l}\text { Cascetta and } \\
\text { Carteni, } 2014\end{array}$ & $\begin{array}{l}\text { Transit } \\
\text { services } \\
\text { quality }\end{array}$ & Campania, Italy & 908 & Field survey & $\begin{array}{l}\text { Passengers with different occupation } \\
\text { have different waiting time perception. }\end{array}$ & Occupation \\
\hline $\begin{array}{l}\text { Varotto et al., } \\
2015\end{array}$ & $\begin{array}{l}\text { Total travel } \\
\text { time }\end{array}$ & Trieste & 3,967 & Field survey & $\begin{array}{l}\text { The means of perceived and actual } \\
\text { travel time do not match for any } \\
\text { modes. Perceived travel time is } \\
\text { overestimated compared to the actual } \\
\text { for all modes except walk. }\end{array}$ & N.A. \\
\hline $\begin{array}{l}\text { Lagune-Reutler et } \\
\text { al., } 2016\end{array}$ & Waiting time & $\begin{array}{l}\text { The Twin Cities, } \\
\text { USA }\end{array}$ & 800 & Field survey & $\begin{array}{l}\text { Passengers tend to overestimate their } \\
\text { waiting times by } 18 \% \text {, with a mean } \\
\text { perceived wait time of } 6.4473 \mathrm{~min} \text { and } \\
\text { a mean actual wait time of } 5.4809 \mathrm{~min} \text {. }\end{array}$ & $\begin{array}{l}\text { Air pollution, traffic } \\
\text { awareness, presence of } \\
\text { mature trees }\end{array}$ \\
\hline Fan et al., 2016 & Waiting time & $\begin{array}{l}\text { Minneapolis and } \\
\text { St. Paul, USA }\end{array}$ & 822 & Field survey & $\begin{array}{l}\text { Perceived waiting time is about } 1.21 \\
\text { times longer than the actual waiting } \\
\text { time on average. }\end{array}$ & $\begin{array}{l}\text { Basic amenities (bench and } \\
\text { sehlter), gender }\end{array}$ \\
\hline
\end{tabular}




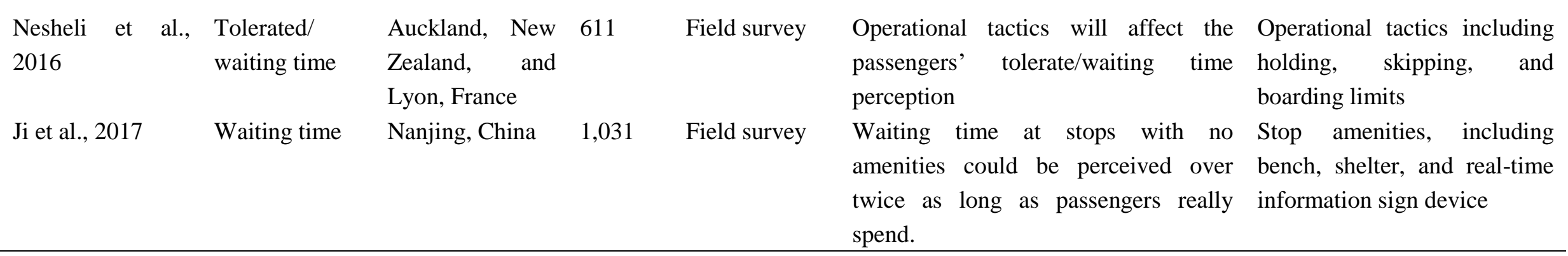


It can be seen from Table 1 that perceived waiting time has been deeply discussed. A general conclusion has been concluded that passengers are easy to perceive more than the actual time when waiting for a public transport service, especially no real-time traffic information is provided (Cheng and Tsai, 2014). The influence factors that affect the waiting time perception vary city by city, where the most common factors are age and peak period. Several studies also found that perceived walking time was often an overestimation of the actual walking time. Influence factors that affect this overestimation may include physical aspects of transfer facilities, such as signage, lighting, circulation lines and characteristics of the surrounding environment (Hall, 2001). Moreover, transfer walking time has shown to be more onerous than first and last mile walking time.

Compared with the burdensome out-of-vehicle time, passengers tend to consider in-vehicle time more acceptable (Chapman et al., 2006). As in-vehicle time is mostly determined by scheduled journey time and vehicle speeds, researchers generally quantity and quality of the value of in-vehicle time in generalised cost equations and the evaluation of stop delay. Little studies have been conduct to check whether there is difference between perceived and actual in-vehicle time.

Overall, these estimations only focused on the single stage analysis (e.g. transfer stage), which doesn't consider the possible causation from other stages. Moreover, some studies used the data from the surveys that conducted sometime later (few hours or one day) after the trip, which is not reliable. This research contributes to the existing literature by examining the relationship between actual and perceived travel time in a multimodal public transport trip, including walking time, waiting time and in-vehicle time with considering the connection of different stages in the whole trip.

\section{Field Survey}

Data were collected by accompany survey through following the respondent from origin to destination. Respondents were selected by the surveyors from either their relatives/friends or the random persons around public transport stations. Surveyor firstly asked the respondent's willingness to participate in this survey, and then made an agreement on the survey time and location. During the trip, the surveyor followed the respondent all the way to the destination. The trip is required to be the respondent's frequent trip, which ensures that the respondent is familiar with all the trip segments. Some rules have been made to ensure the trip to be as natural as possible, such as minimise chatting 
with the respondent except questioning, follow the respondent behind and not side by side, try to measure the actual time without the respondent knowing.

Detailed information were recorded including trip start and end time, date, weather, location, trip purpose and facility usage in the trip, as well as socioeconomic attributes like age, gender, occupation. Actual travel time at each stage was measured by stopwatch, while perceived travel time at each stage was recorded by asking the respondent right after each action performed. Below are the variables and the corresponding data input codes that are used in the survey:

1. Perceived walking time, actual waiting time and actual in-vehicle time at each stage (continuous variable);

2. Actual walking time, actual waiting time and actual in-vehicle time at each stage (continuous variable );

3. Travel distance (continuous variable );

4. Travel Date (Travel Date $=0$ : weekdays, and Travel Date $=1$ : weekend);

5. Weather (Weather $=0$ : poor weather, like cloudy, drizzle, and rainy, Weather $=1$ : sunny);

6. Purpose (Purpose $=0$ : non-commuter trip, to home/recreation/personal business, to work/school, Purpose =1: commuter trip);

7. Age (Age =0: $<20$, Age $=1: 21-30$, Age $=2: 31-40$, Age $=3: 41-50$, Age $=4:>51)$;

8. Gender (Gender $=0$ : male and Gender $=1$ : female $)$;

9. Occupation (Occupation $=0$ : employment, Occupation $=1$ : non-employment, like student, housewife, and retired);

10. Number of transfer (Number of transfer $=0$ : one transfer, Number of transfer $=1$ : two transfer);

11. Travel mode (Travel mode $=0$ : MRT-based trip, Travel mode $=1$ : bus-based trip);

12. Travel period (Travel period $=0$ : peak hour, 6:30 to 9:00 and 17:00 to 19:30, and Travel period $=1$ : off peak);

13. Facilities usage related with walking;

a. Covered shelter or coved facility (Covered shelter $=0$ : yes, and Covered shelter $=1$ : no); 
b. Elevator or escalator (Elevator $=0$ : yes, and Elevator =1: no);

c. Stairs (Stairs $=0$ : yes, and Stairs $=1$ : no);

d. $\quad$ ATM or stores $(\mathrm{ATM}=0$ : yes, and $\mathrm{ATM}=1$ : no);

14. Facilities usage related with waiting;

a. Arrival time panel or other information system (Information =0: yes, and Information =1: no);

b. Seat $($ Seat $=0$ : yes, and Seat $=1:$ no $)$;

c. Aircon environment (Aircon =0: yes, and Aircon =1:no).

The survey was undertaken from December 2015 to February 2016. In total, 437 available trips (316 trips with 1 time transfer only, 109 trips with 2 times transfer, and 12 trips with 3 times transfer) were collected. Considering the small portion of 3 times transfer trips, 425 data of 1 time and 2 times transport trips were used in the analysis and modelling.

Preliminary statistical analysis revealed a relative balance between male and female passengers $46 \%$ versus $54 \%$ according to the national proportion $49 \%$ versus $51 \%$. Travellers' age and distribution are also in line with the national household travel survey results, where the youth, adult and elderly account for $24 \%, 59 \%$ and $17 \%$ respectively, and the employed traveller accounts for 52\% in all travellers. $50 \%$ of the trips were for commute purpose, which is not slight less than the results from national household travel survey (73\%). It is not surprisingly as the passengers prefer to be followed during non-peak period.

Considering the total travel time, as shown in Figure 2, the average actual and perceived travel time are 66.2 and $69.6 \mathrm{~min}$, respectively. The out-of-vehicle time accounts for $40.3 \%$ and $41.8 \%$ in average actual and perceived travel time. Breaking the perceived out-of-vehicle time down even further, traveller usually perceived that he/she walks $5.4 \mathrm{~min}(7.7 \%)$ and waits $6.0 \mathrm{~min}(8.6 \%)$ in first mile, walks $4.1 \mathrm{~min}(6.0 \%)$ and waits $6.8 \mathrm{~min}(9.8 \%)$ during transfer and walks $6.8 \mathrm{~min}(9.8 \%)$ in last mile. The significant amount of transfer travel time with a proportion of $18.4 \%$ of total travel time clearly shows the importance of transfer in total travel time, which has been also reported in other studies (Anderson et al., 2014; Debrezion et al., 2009). 


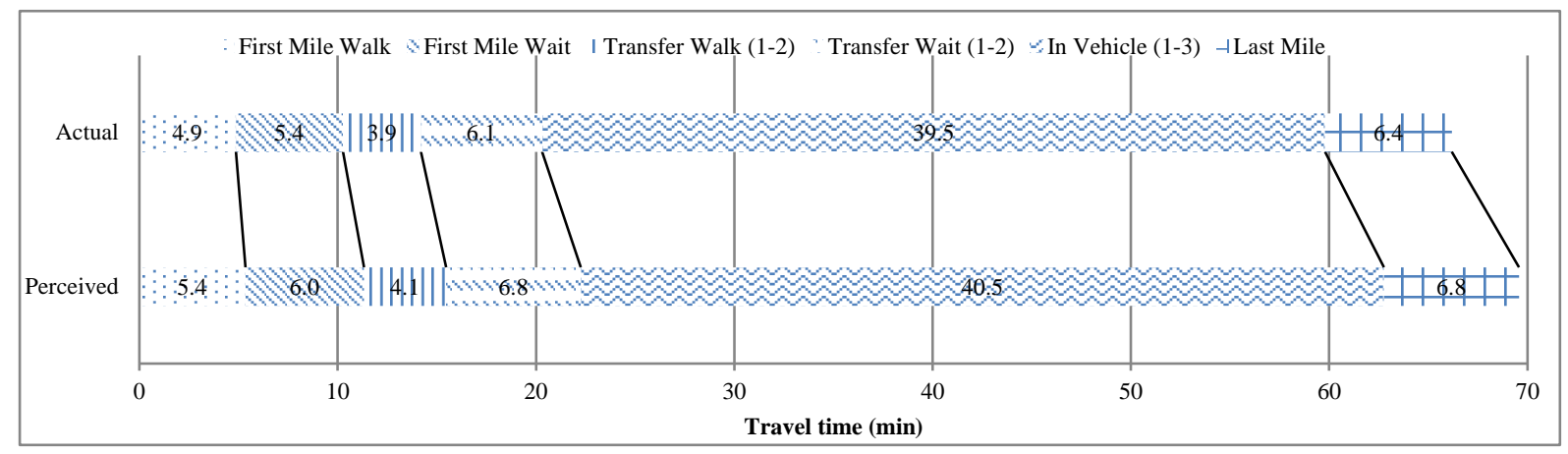

Figure 2 Actual and perceived travel Time at each trip segment

Table 2 summarises the perceived and actual average travel time at each stage for different sociological attributes and trip characteristics. By inspecting Table 2 results, in general, perceived travel time is greater than the actual travel time at each stage. Passengers have more accurate perception while in-vehicle compared with out-of-vehicle. Specifically, passengers usually perceive more during waiting than walking (1.11 and 1.11 versus $1.10,1.05$ and 1.07$)$. The overall analysis could provide qualitatively understanding of the perceptions by specific groups. Such as, women tend to overestimate their walking time, waiting time and in-vehicle time than men.

Table 2 Perceived and actual average travel time (in min) for different sociological attribute and trip characteristics

\begin{tabular}{|c|c|c|c|c|c|c|c|c|c|}
\hline & $\begin{array}{l}\text { AFM } \\
\text { K }\end{array}$ & $\begin{array}{l}\text { PFM } \\
\mathrm{K}\end{array}$ & $\begin{array}{l}\text { PFMK/ } \\
\text { AFMK }\end{array}$ & $\begin{array}{l}\text { AFM } \\
\mathrm{T}\end{array}$ & $\begin{array}{l}\text { PFM } \\
\mathrm{T}\end{array}$ & $\begin{array}{l}\text { PFMT/ } \\
\text { AFMT }\end{array}$ & AIV & PIV & $\begin{array}{l}\text { PIV/ } \\
\text { AIV }\end{array}$ \\
\hline \multicolumn{10}{|l|}{ Age } \\
\hline$<20$ & 5.05 & 5.60 & 1.11 & 5.54 & 5.92 & 1.07 & 38.45 & 38.98 & 1.01 \\
\hline $20-30$ & 4.95 & 5.35 & 1.08 & 5.54 & 6.11 & 1.10 & 42.32 & 43.55 & 1.03 \\
\hline $31-40$ & 5.10 & 5.81 & 1.14 & 4.93 & 5.52 & 1.12 & 37.59 & 37.80 & 1.01 \\
\hline $41-50$ & 5.01 & 5.34 & 1.07 & 6.20 & 6.70 & 1.08 & 40.39 & 41.23 & 1.02 \\
\hline$>51$ & 3.68 & 4.31 & 1.17 & 4.26 & 5.29 & 1.24 & 28.47 & 30.51 & 1.07 \\
\hline \multicolumn{10}{|l|}{ Gender } \\
\hline Men & 4.98 & 5.35 & 1.07 & 5.61 & 6.16 & 1.10 & 42.10 & 43.18 & 1.03 \\
\hline Women & 4.77 & 5.35 & 1.12 & 5.22 & 5.83 & 1.12 & 37.35 & 38.31 & 1.03 \\
\hline \multicolumn{10}{|l|}{ Purpose } \\
\hline $\begin{array}{l}\text { To work/ } \\
\text { school }\end{array}$ & 4.83 & 5.17 & 1.07 & 6.00 & 6.85 & 1.14 & 43.85 & 44.73 & 1.02 \\
\hline Other & 4.88 & 5.40 & 1.11 & 5.23 & 5.75 & 1.10 & 38.34 & 39.39 & 1.03 \\
\hline \multicolumn{10}{|c|}{ Occupation } \\
\hline Employed & 5.06 & 5.66 & 1.12 & 5.09 & 5.77 & 1.13 & 37.27 & 38.43 & 1.03 \\
\hline Others & 4.71 & 5.11 & 1.08 & 5.63 & 6.14 & 1.09 & 41.23 & 42.13 & 1.02 \\
\hline
\end{tabular}




\begin{tabular}{|c|c|c|c|c|c|c|c|c|c|}
\hline \multicolumn{10}{|l|}{ Peak } \\
\hline Peak hour & 4.83 & 5.28 & 1.09 & 5.28 & 5.93 & 1.12 & 40.31 & 41.80 & 1.04 \\
\hline $\begin{array}{l}\text { Off-peak } \\
\text { hour }\end{array}$ & 4.89 & 5.40 & 1.10 & 5.47 & 6.01 & 1.10 & 38.95 & 39.66 & 1.02 \\
\hline \multicolumn{10}{|l|}{ Date } \\
\hline Weekend & 4.77 & 5.27 & 1.10 & 5.42 & 6.05 & 1.12 & 40.00 & 41.24 & 1.03 \\
\hline Weekdays & 5.11 & 5.54 & 1.08 & 5.33 & 5.80 & 1.09 & 38.20 & 38.67 & 1.01 \\
\hline \multirow[t]{3}{*}{ Total } & 4.87 & 5.35 & 1.10 & 5.40 & 5.98 & 1.11 & 39.48 & 40.50 & 1.03 \\
\hline & ATR & PTR & PTRK/ & ATR & $\begin{array}{l}\text { PTR } \\
\end{array}$ & PTRT/ & ALM & PLM & PLMK/ \\
\hline & $\mathrm{K}$ & $\mathrm{K}$ & ATRK & $\mathrm{T}$ & $\mathrm{T}$ & ATRT & $\mathrm{K}$ & $\mathrm{K}$ & ALMK \\
\hline \multicolumn{10}{|l|}{ Age } \\
\hline$<20$ & 3.38 & 3.75 & 1.11 & 6.21 & 6.47 & 1.05 & 6.51 & 6.72 & 1.03 \\
\hline $20-30$ & 3.78 & 3.90 & 1.03 & 6.60 & 7.45 & 1.12 & 6.50 & 6.90 & 1.06 \\
\hline $31-40$ & 4.04 & 4.18 & 1.03 & 5.11 & 5.45 & 1.09 & 6.37 & 7.02 & 1.10 \\
\hline $41-50$ & 4.24 & 4.38 & 1.03 & 6.43 & 7.38 & 1.12 & 6.35 & 6.88 & 1.08 \\
\hline$>51$ & 4.95 & 5.62 & 1.14 & 4.62 & 5.26 & 1.19 & 5.74 & 6.04 & 1.05 \\
\hline \multicolumn{10}{|l|}{ Gender } \\
\hline Men & 3.86 & 4.09 & 1.06 & 5.94 & 6.47 & 1.09 & 6.27 & 6.53 & 1.04 \\
\hline Women & 3.98 & 4.19 & 1.05 & 6.32 & 7.18 & 1.14 & 6.48 & 7.03 & 1.08 \\
\hline \multicolumn{10}{|l|}{ Purpose } \\
\hline $\begin{array}{l}\text { To work/ } \\
\text { school }\end{array}$ & 4.23 & 4.57 & 1.08 & 6.45 & 7.25 & 1.12 & 6.95 & 6.99 & 1.01 \\
\hline Other & 3.85 & 4.03 & 1.05 & 6.02 & 6.67 & 1.11 & 6.24 & 6.76 & 1.08 \\
\hline \multicolumn{10}{|c|}{ Occupation } \\
\hline Employed & 4.12 & 4.42 & 1.07 & 5.57 & 6.28 & 1.13 & 6.26 & 6.85 & 1.09 \\
\hline Others & 3.77 & 3.92 & 1.04 & 6.53 & 7.19 & 1.10 & 6.49 & 6.77 & 1.04 \\
\hline \multicolumn{10}{|l|}{ Peak } \\
\hline Peak hour & 4.16 & 4.33 & 1.04 & 6.24 & 6.98 & 1.12 & 6.69 & 7.08 & 1.06 \\
\hline $\begin{array}{l}\text { Off-peak } \\
\text { hour }\end{array}$ & 3.78 & 4.02 & 1.06 & 6.02 & 6.66 & 1.11 & 6.20 & 6.63 & 1.07 \\
\hline \multicolumn{10}{|l|}{ Date } \\
\hline Weekend & 3.93 & 4.16 & 1.06 & 6.05 & 6.73 & 1.11 & 6.47 & 6.73 & 1.04 \\
\hline Weekdays & 3.92 & 4.10 & 1.05 & 6.25 & 6.92 & 1.11 & 6.19 & 6.98 & 1.13 \\
\hline Total & 3.93 & 4.14 & 1.05 & 6.11 & 6.79 & 1.11 & 6.39 & 6.81 & 1.07 \\
\hline
\end{tabular}

AFMK: Actual first mile walking time; PFMK: Perceived first mile walking time; AIV: Actual in-vehicle travel time; PIV:

Perceived in-vehicle travel time; ATRK: Actual transfer walking time; PTRK: Perceived transfer walking time; ALMK:

Actual last mile walking time; PLMK: Perceived last mile walking time. 
To check if there is difference between the actual and perceived travel time for walking, waiting and in-vehicle time, a series of paired T-test is used. The hypothesis is that there is no difference between the actual travel time and perceived travel time for all travel time components in the public transit trip:

$$
\mathrm{H}_{0}: \mu_{\text {percieved time }}-\mu_{\text {actual time }}=0
$$

From the results of the series of T-test in Table 3, the hypotheses that the perceived travel time at each stage is equal to the corresponding actual travel time are rejected. Taking the first mile walking time analysis as an example, as the p-value is less than $0.05(<0.0001)$, it can be concluded that there is a statistically significant difference between the perceived first mile walking time and the actual first mile walking time. In other words, the difference between the perceived first mile walking time and the actual first mile walking time is not equal to zero. There is a mean 0.48 min difference between the perceived first mile walking time and the actual first mile walking time with a standard deviation of 1.42 min and $95 \%$ confidence intervals of 0.35 to 0.62 .

Table 3 Results of T-test for each trip stage

\begin{tabular}{llll}
\hline Variable & Mean & Std. Dev & 95\% CL Mean \\
\hline First mile walking time & & & \\
Actual & 4.87 & 3.38 & $4.55-5.19$ \\
Perceived & 5.35 & 3.97 & $4.97-5.73$ \\
Difference & 0.48 & 1.42 & $0.35-0.62$ \\
No. observations $=425, \mathrm{t}=7.01, \operatorname{Pr}(\mathrm{T}>\mathrm{t})<0.0001$ & & \\
\hline
\end{tabular}

\section{First mile waiting time}

$\begin{array}{llll}\text { Perceived } & 5.39 & 3.76 & 5.03-5.75 \\ \text { Actual } & 5.98 & 4.26 & 5.57-6.38 \\ \text { Difference } & 0.59 & 1.50 & 0.44-0.73\end{array}$

No. observations $=425, \mathrm{t}=8.05, \operatorname{Pr}(\mathrm{T}>\mathrm{t})<0.0001$

\section{First transfer walking time}

$\begin{array}{llll}\text { Actual } & 2.96 & 2.44 & 2.73-3.19 \\ \text { Perceived } & 3.12 & 2.66 & 2.87-3.37 \\ \text { Difference } & 0.16 & 1.01 & 0.06-0.26\end{array}$

No. observations $=425, \mathrm{t}=3.25, \operatorname{Pr}(\mathrm{T}>\mathrm{t})=0.0012$

\section{First transfer waiting time}

$\begin{array}{llll}\text { Actual } & 4.99 & 3.92 & 4.62-5.36 \\ \text { Perceived } & 5.55 & 4.56 & 5.12-5.99 \\ \text { Difference } & 0.56 & 1.57 & 0.41-0.71\end{array}$

No. observations $=425, \mathrm{t}=7.40, \operatorname{Pr}(\mathrm{T}>\mathrm{t})<0.0001$ 


\begin{tabular}{|c|c|c|c|}
\hline \multicolumn{4}{|c|}{ Second transfer walking time } \\
\hline Actual & 3.77 & 1.83 & $3.42-4.12$ \\
\hline Perceived & 3.99 & 2.07 & $3.59-4.38$ \\
\hline Difference & 0.22 & 0.95 & $0.04-0.40$ \\
\hline \multicolumn{4}{|c|}{ No. observations $=109, \mathrm{t}=2.38, \operatorname{Pr}(\mathrm{T}>\mathrm{t})=0.019$} \\
\hline \multicolumn{4}{|c|}{ Second transfer waiting time } \\
\hline Actual & 4.36 & 3.55 & $3.68-5.03$ \\
\hline Perceived & 4.82 & 3.87 & $4.08-5.55$ \\
\hline Difference & 0.46 & 1.18 & $0.24-0.69$ \\
\hline \multicolumn{4}{|c|}{ No. observations $=109, \mathrm{t}=4.07, \operatorname{Pr}(\mathrm{T}>\mathrm{t})<0.0001$} \\
\hline \multicolumn{4}{|c|}{ First in-vehicle time } \\
\hline Actual & 16.48 & 13.31 & $15.21-17.75$ \\
\hline Perceived & 17.03 & 13.92 & $15.70-18.36$ \\
\hline Difference & 0.55 & 2.54 & $0.30-0.79$ \\
\hline \multicolumn{4}{|c|}{ No. observations $=425, \mathrm{t}=4.43, \operatorname{Pr}(\mathrm{T}>\mathrm{t})<0.0001$} \\
\hline \multicolumn{4}{|c|}{ Second in-vehicle time } \\
\hline Actual & 20.40 & 14.66 & $19.00-21.80$ \\
\hline Perceived & 20.93 & 15.09 & $19.49-22.37$ \\
\hline Difference & 0.53 & 2.88 & $0.26-0.81$ \\
\hline \multicolumn{4}{|c|}{ No. observations $=425, \mathrm{t}=3.81, \operatorname{Pr}(\mathrm{T}>\mathrm{t})=0.0002$} \\
\hline \multicolumn{4}{|c|}{ Third in-vehicle time } \\
\hline Actual & 10.13 & 8.77 & $8.46-11.79$ \\
\hline Perceived & 10.64 & 8.57 & $9.01-12.27$ \\
\hline Difference & 0.25 & 1.71 & $0.07-0.58$ \\
\hline \multicolumn{4}{|c|}{ No. observations $=109, \mathrm{t}=3.41, \operatorname{Pr}(\mathrm{T}>\mathrm{t})=0.0009$} \\
\hline \multicolumn{4}{|c|}{ Last mile walking time } \\
\hline Actual & 6.39 & 4.89 & $5.92-6.85$ \\
\hline Perceived & 6.81 & 5.63 & $6.27-7.34$ \\
\hline Difference & 0.42 & 2.03 & $0.22-0.61$ \\
\hline No. observa & $\mathrm{t}=4.23, \mathrm{I}$ & & \\
\hline
\end{tabular}

Then we analyse the total walking, waiting and in-vehicle time by considering it at all relevant stages. As shown in Table 4, the hypothesis that the perceived total walking time is equal to the actual total walking time is rejected, same for total waiting time and total in-vehicle time. On average, passenger perceives that he/she is walking $1.12 \mathrm{~min}$ and waiting $1.27 \mathrm{~min}$ longer and spending in-vehicle 1.02 min longer than he/she actually is. From this, we can answer the first research question that there are always perception differences for all travel time components. 
Table 4 Results of T-test for all relevant stages

\begin{tabular}{lccc}
\hline Total walking time & & & \\
Actual & 15.18 & 7.06 & $14.51-15.86$ \\
Perceived & 16.30 & 8.13 & $15.52-17.07$ \\
Difference & 1.12 & 3.04 & $0.83-1.41$ \\
No. observations $=425, \mathrm{t}=7.56, \operatorname{Pr}(\mathrm{T}>\mathrm{t})<0.0001$ & & \\
\hline Total waiting time & & & \\
Actual & 11.50 & 6.69 & $10.86-12.14$ \\
Perceived & 12.77 & 7.66 & $12.04-13.50$ \\
Difference & 1.27 & 2.48 & $1.03-1.50$ \\
No. observations $=425, \mathrm{t}=10.54, \operatorname{Pr}(\mathrm{T}>\mathrm{t})<0.0001$ & \\
\hline Total in-vehicle time & & & $37.74-41.22$ \\
Actual & 39.48 & 18.24 & $38.71-42.28$ \\
Perceived & 18.69 & $0.74-1.54$ \\
Difference & 40.50 & 4.25 & \\
No. observations $=425, \mathrm{t}=4.92, \operatorname{Pr}(\mathrm{T}>\mathrm{t})<0.0001$ & & \\
\hline
\end{tabular}

\section{Linear Regression Model}

Modelling the travel time component on each trip stage is not instructive to planners. For example, traveller A's first transfer stage might be the second transfer stage for traveller B. To quantify the perceived travel time, it is reasonable to model the same travel time component by considering it at different stages. An issue arises naturally, that is, whether or not the travel time experienced before the trip stage will affect the travel time perception on this stage. For example, will the actual first transfer walking time affect the first transfer waiting time perception? A set of correlation analysis is applied, in which the dependent variables include all the perceived travel time at each stage. As shown in Table 5, the perceived travel time is only highly correlated to the actual travel time at the current stage (Pearson correlation coefficient $>0.9$ and p-value $<0.0001$ ). Hence, we can conclude that the travel time perception at the current stage is very little (or hardly) affected by the travel time experienced in previous stage. Therefore, we can model the same travel time component perception by adding it from all relevant trip stages, e.g. waiting time at each stage. 
Table 5 Results of correlation analysis

\begin{tabular}{|c|c|c|}
\hline Variable & Pearson Correlation Coefficient & p-value \\
\hline \multicolumn{3}{|l|}{ Perceived first mile walking time } \\
\hline Actual first mile walking time & 0.93756 & $<0.0001$ \\
\hline \multicolumn{3}{|l|}{ Perceived first mile waiting time } \\
\hline Actual first mile walking time & 0.03366 & 0.4889 \\
\hline Actual first mile waiting time & 0.93745 & $<0.0001$ \\
\hline \multicolumn{3}{|l|}{ Perceived first in-vehicle time } \\
\hline Actual first mile walking time & 0.11132 & 0.0217 \\
\hline Actual first mile waiting time & 0.26693 & $<0.0001$ \\
\hline Actual first in-vehicle time & 0.98355 & $<0.0001$ \\
\hline \multicolumn{3}{|l|}{ Perceived first transfer walking time } \\
\hline Actual first mile walking time & -0.05968 & 0.2195 \\
\hline Actual first mile waiting time & -0.21079 & $<0.0001$ \\
\hline Actual first in-vehicle time & -0.17983 & 0.0002 \\
\hline Actual first transfer walking time & 0.92523 & $<0.0001$ \\
\hline \multicolumn{3}{|l|}{ Perceived first transfer waiting time } \\
\hline Actual first mile walking time & 0.14043 & 0.0037 \\
\hline Actual first mile waiting time & 0.37727 & $<0.0001$ \\
\hline Actual first in-vehicle time & 0.29774 & $<0.0001$ \\
\hline Actual first transfer walking time & 0.26189 & $<0.0001$ \\
\hline Actual first transfer waiting time & 0.94290 & $<0.0001$ \\
\hline \multicolumn{3}{|l|}{ Perceived second in-vehicle time } \\
\hline Actual first mile walking time & -0.04974 & 0.3063 \\
\hline Actual first mile waiting time & 0.16569 & 0.0006 \\
\hline Actual first in-vehicle time & -0.17834 & 0.0002 \\
\hline Actual second transfer walking time & -0.11357 & 0.2396 \\
\hline Actual second transfer waiting time & 0.05461 & 0.5727 \\
\hline Actual second in-vehicle time & 0.98170 & $<0.0001$ \\
\hline \multicolumn{3}{|c|}{ Perceived second transfer walking time } \\
\hline Actual first mile walking time & 0.08520 & 0.3784 \\
\hline Actual first mile waiting time & 0.11447 & 0.2359 \\
\hline Actual first in-vehicle time & -0.02417 & 0.8030 \\
\hline Actual first transfer walking time & 0.26252 & 0.0058 \\
\hline Actual first transfer waiting time & -0.04005 & 0.6792 \\
\hline Actual second in-vehicle time & -0.15403 & 0.1098 \\
\hline Actual second transfer walking time & 0.91877 & $<0.0001$ \\
\hline \multicolumn{3}{|c|}{ Perceived second transfer waiting time } \\
\hline Actual first mile walking time & 0.13770 & 0.1533 \\
\hline Actual first mile waiting time & 0.12569 & 0.1928 \\
\hline Actual first in-vehicle time & -0.01072 & 0.9119 \\
\hline Actual first transfer walking time & 0.11415 & 0.2372 \\
\hline
\end{tabular}


Actual first transfer waiting time

Actual second in-vehicle time

Actual second transfer walking time

Actual second transfer waiting time

\section{Perceived third in-vehicle time}

Actual first mile walking time

Actual first mile waiting time

Actual first in-vehicle time

Actual first transfer walking time

Actual first transfer waiting time

Actual second in-vehicle time

Actual second transfer walking time

Actual second transfer waiting time

Actual third in-vehicle time

Perceived last mile walking time

Actual first mile walking time

Actual first mile waiting time

Actual first in-vehicle time

Actual first transfer walking time

Actual first transfer waiting time

Actual second in-vehicle time

Actual second transfer walking time

Actual second transfer waiting time

Actual third in-vehicle time

Actual last mile walking time

$\begin{array}{ll}0.26168 & 0.0060 \\ 0.00632 & 0.9480 \\ 0.02574 & 0.7905 \\ \mathbf{0 . 9 5 2 8 0} & <\mathbf{0 . 0 0 0 1} \\ & \\ 0.01298 & 0.8934 \\ 0.02812 & 0.7716 \\ 0.03470 & 0.7201 \\ -0.08174 & 0.3981 \\ -0.03075 & 0.7509 \\ -0.08988 & 0.3526 \\ -0.08958 & 0.3543 \\ 0.16131 & 0.0938 \\ \mathbf{0 . 9 8 0 8 1} & <\mathbf{0 . 0 0 0 1}\end{array}$

$0.19081<0.0001$

$0.14573 \quad 0.0026$

$0.06524 \quad 0.1795$

$0.05324 \quad 0.2735$

$0.07161 \quad 0.1405$

$0.02769-0.5691$

$0.20837 \quad 0.0297$

$-0.02058 \quad 0.8318$

$-0.11593 \quad 0.2300$

A set of scatter plot diagrams is given in Figure 3 to show the general relationship between the perceived travel time and actual travel time. It could be found that there is a strong linear relationship between the perceived travel time and actual travel time for all travel time component. Therefore, to find out which factor could affect the travel time perception, and how to quantify the perception, three linear regression models can be developed to quantify the perceived walking, waiting and in-vehicle time based on the actual walking, waiting and in-vehicle time, as well as other potential influence factors. Stepwise selection method in SAS® (a statistical analysis system) is used to determine the final models:

$$
\begin{aligned}
& y_{k}=\beta_{1 \mathrm{k}} x_{1 \mathrm{k}}+\beta_{2 \mathrm{k}} x_{2 \mathrm{k}}+\beta_{3 \mathrm{k}} x_{3 \mathrm{k}}+\cdots \beta_{n k} x_{n k}+\varepsilon_{k} \\
& y_{t}=\beta_{1 \mathrm{t}} x_{1 \mathrm{t}}+\beta_{2 \mathrm{t}} x_{2 \mathrm{t}}+\beta_{3 \mathrm{t}} x_{3 \mathrm{t}}+\cdots \beta_{n t} x_{n t}+\varepsilon_{t} \\
& y_{i}=\beta_{1 \mathrm{i}} x_{1 \mathrm{i}}+\beta_{2 \mathrm{i}} x_{2 \mathrm{i}}+\beta_{3 \mathrm{i}} x_{3 \mathrm{i}}+\cdots \beta_{n i} x_{n i}+\varepsilon_{i}
\end{aligned}
$$


where $y_{k}, y_{t}$ and $y_{i}$ are the dependent variables and represent perceived walking, waiting and in-vehicle time respectively. $\beta_{1 k} \ldots \beta_{n k}, \quad \beta_{1 t} \ldots \beta_{n t}, \beta_{1 i} \ldots \beta_{n i}$ are the coefficients of independent variables, $\varepsilon_{k}, \varepsilon_{t}, \varepsilon_{i}$ are the error terms, $x_{1 k} \ldots x_{n k}, x_{1 t} \ldots x_{n t}, x_{1 i} \ldots x_{n i}$ are the independent variables which are the variables 2-14 as listed in section 3 .
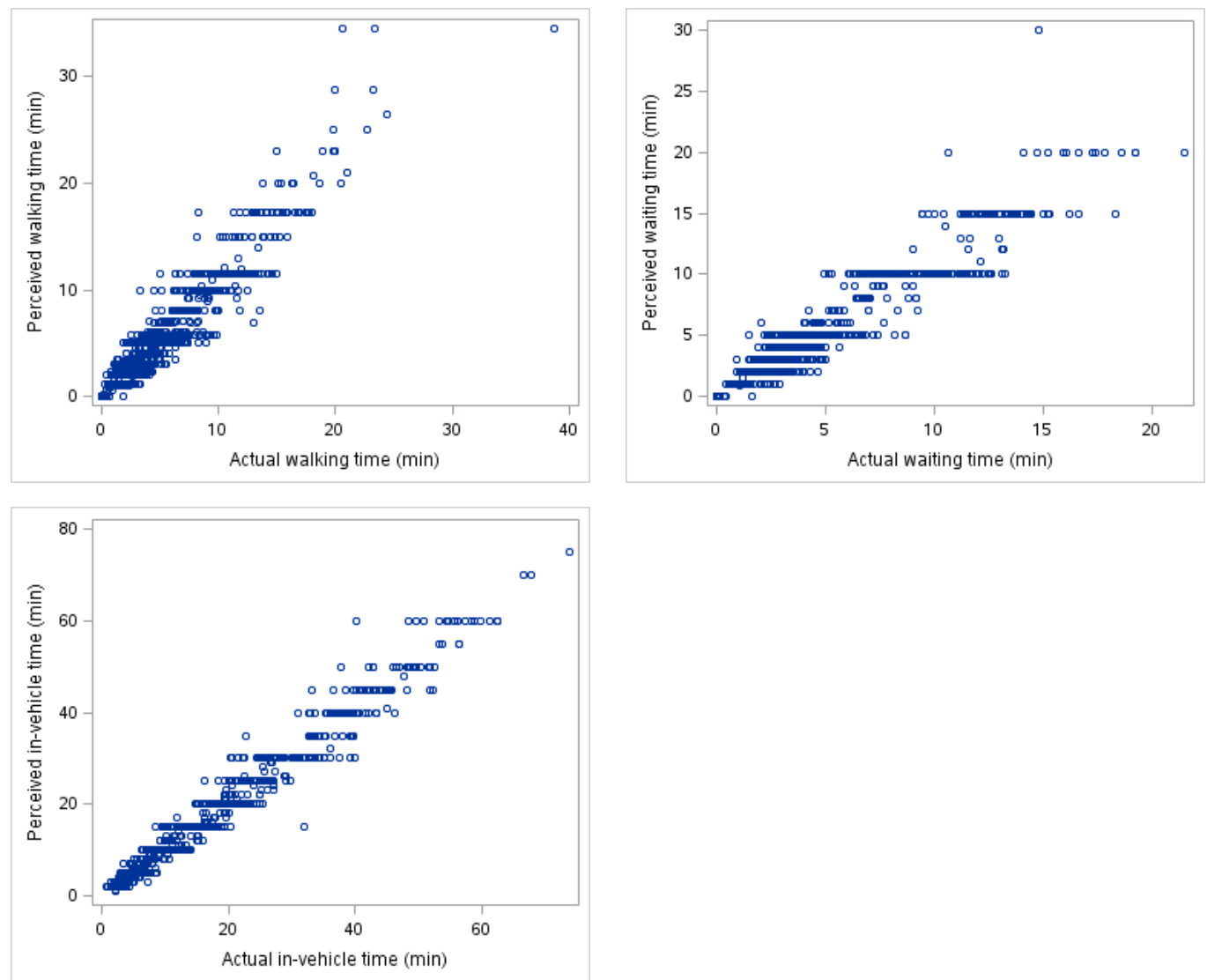

Figure 3 A set of scatter plot diagrams

\subsection{Perceived Walking Time Modelling}

The influencing variables related with the walking stage are included in the modelling by stepwise selection method. A stepwise method is a proper method for this analysis because of finding the best combination of the attributes by adding and removing the attributes until the selection model achieved based on the predefined requirements. It automatically selects the variable to be added to or removed from the model of regression analysis. Selection stopped when the candidate for entry has SLE (significance level for entry into the model) $>0.05$ and the candidate for removal has SLS (Significance Level for Staying in the model) $<0.05$. Apart from automatic selection option in SAS, the variables are also put into the model one by one together with the variable Distance to check the impact on time perception in short and long trips. Possible interaction terms (based on statistical and 
practical considerations) such as Distance*Age and Distance*Gender also were checked. The steps were repeated until there were no other variables that could improve the adjusted $\mathrm{R}^{2}$ of the model. The final results in Table 6 show that actual walking time, travel distance, occupation, elevator usage, weather, trip purpose and covered shelter usage will affect the perception of walking time. The estimated model is listed in Table 7 with an overall adjusted $\mathrm{R}^{2} 0.9512$. The model performs well on the diagnostic tests. On average, passenger perceives he/she is walking $1.0743 \mathrm{~min}$ for every minute he/she actually walks. Long distance trip decreases the walking perception. Moreover, passenger perceives that he/she is walking $0.2069 \mathrm{~min}$ more if the weather is poor, $0.2632 \mathrm{~min}$ less if the trip is for non-commuter purpose, $0.1962 \mathrm{~min}$ less if he/she uses elevator and 0.1760 less if he/she uses covered sheltered. Employment group perceives walking 0.2232 min more than non-employment group. According to the results, it is necessary to provide elevator at MRT stations to minimise passengers' walking time perception.

Table 6 Stepwise selection results

\begin{tabular}{llll}
\hline Variable & Adjusted $\mathrm{R}^{2}$ & $t$-Statistic & $p$-value \\
\hline Actual walking time & 0.9501 & 26350.3 & $<.0001$ \\
Distance & 0.9502 & 4.18 & 0.0412 \\
Occupation & 0.9506 & 6.96 & 0.0010 \\
Elevator & 0.9508 & 4.47 & 0.0346 \\
Weather & 0.9509 & 4.29 & 0.0385 \\
Purpose & 0.9511 & 6.05 & 0.0140 \\
Covered shelter & $0.9512^{*}$ & 4.06 & 0.0442 \\
\hline
\end{tabular}

* Optimal Value of Criterion

Table 7 Estimation results for perceived walking time

\begin{tabular}{lllll}
\hline Variable & Coefficient & Std. Err & $t$-Statistic & $p$-value \\
\hline Actual walking time & 1.0743 & 0.0103 & 103.87 & $<.0001$ \\
Distance & -0.0192 & 0.0060 & -3.20 & 0.0014 \\
Occupation 0 (ref Occupation =1) & 0.2232 & 0.0817 & 2.73 & 0.0064 \\
Elevator 0 (ref Elevator =1) & -0.1962 & 0.0812 & -2.42 & 0.0159 \\
Weather 0 (ref Weather =1) & 0.2069 & 0.0809 & 2.56 & 0.0107 \\
Purpose 0 (ref Purpose =1) & -0.2632 & 0.1022 & -2.57 & 0.0101 \\
Covered shelter 0 (ref Covered shelter =1) & -0.1760 & 0.0874 & -2.01 & 0.0442 \\
No. observations = 1384, Adj $\mathrm{R}^{2}=0.9514, \mathrm{~F}$ value $=3370.58, \operatorname{Pr}(\mathrm{T}>\mathrm{t})<0.0001$ & \\
\hline
\end{tabular}




\subsection{Perceived Waiting Time Modelling}

Similarly, the results in Table 8 show that actual waiting time, age, trip distance and arrival time panel usage will affect the perception of waiting time. The estimated model is listed in Table 9 with an overall adjusted $\mathrm{R}^{2} 0.9586$. On average, passenger perceives he/she is waiting $1.0738 \mathrm{~min}$ for every minute he/she actually waits. Long distance trip decreases the waiting time perception. Youth generation tends to perceive waiting less than the elderly. If passenger has the access to the arrival information, he/she perceives waiting $0.2678 \mathrm{~min}$ less. From the insignificant variables, it could be found that the number of transfer times will not affect the waiting time perception. It means that the perception difference may not relevant to the standing location in the trip. Meanwhile, unlike some other research outcomes, the results indicate that gender and trip purpose do not affect the waiting time perception. For operators, arrival information board with real time traffic information is needed to facilitate passengers waiting at the public transport stations.

Table 8 Stepwise selection results

\begin{tabular}{llll}
\hline Variable & Adjusted $\mathrm{R}^{2}$ & $t$-Statistic & $p$-value \\
\hline Actual waiting time & 0.9576 & 21637.7 & $<.0001$ \\
Age & 0.9580 & 2.85 & 0.0146 \\
Distance & 0.9581 & 4.26 & 0.0393 \\
Information & $0.9583^{*}$ & 4.44 & 0.0354 \\
\hline
\end{tabular}

* Optimal Value of Criterion

Table 9 Estimation results for perceived waiting time

\begin{tabular}{|c|c|c|c|c|}
\hline Variable & Coefficient & Std. Err & $t$-Statistic & $p$-value \\
\hline Distance & -0.0170 & 0.0072 & -2.36 & 0.0186 \\
\hline Actual waiting time & 1.0738 & 0.0128 & 83.63 & $<.0001$ \\
\hline Age $0($ ref Age $=4)$ & -0.5972 & 0.2015 & -2.96 & 0.0031 \\
\hline Age 1 (ref Age=4) & -0.2049 & 0.1701 & -1.20 & 0.2289 \\
\hline Age $2($ ref Age $=4)$ & -0.3618 & 0.1947 & -1.86 & 0.0635 \\
\hline Age $3($ ref Age=4) & -0.2330 & 0.2072 & -1.12 & 0.2612 \\
\hline Information $0($ ref Information $=1)$ & -0.2678 & 0.1271 & -2.11 & 0.0354 \\
\hline \multicolumn{5}{|c|}{ No. observations $=959$, Adj $R^{2}=0.9586, F$ value $=2752.93, \operatorname{Pr}(T>t)<0.0001$} \\
\hline
\end{tabular}

\subsection{Perceived In-vehicle Time Modelling}

The results in Table 10 show that only actual in-vehicle time and peak hour will affect the perception of in-vehicle time. The estimated model is listed in Table 11 with an overall adjusted $\mathrm{R}^{2}$ 
0.9669. On average, passenger perceives he/she is spending $1.019 \mathrm{~min}$ for every minute he/she actually spends in vehicle. Passenger perceives spending 0.3410 min more if the trip is conducted in peak hours. From the insignificant variables, it could be found that socioeconomic characteristics factors and facility usage factors do not affect the in-vehicle travel time perception.

Table 10 Stepwise selection results

\begin{tabular}{llll}
\hline Variable & Adjusted $\mathrm{R}^{2}$ & $t$-Statistic & $p$-value \\
\hline Actual in-vehicle time & 0.9668 & 27912.6 & $<.0001$ \\
Travel period & $0.9669^{*}$ & 3.89 & 0.0490 \\
\hline
\end{tabular}

* Optimal Value of Criterion

Table 11 Estimation results for perceived in-vehicle time

\begin{tabular}{lllll}
\hline Variable & Coefficient & Std. Err & $t$-Statistic & $p$-value \\
\hline Actual in-vehicle time & 1.019 & 0.0061 & 167.26 & $<.0001$ \\
Travel period $\quad$ 0 (ref Travel period =1) & 0.3410 & 0.1730 & 1.97 & 0.0490 \\
No. observations = 959, Adj $\mathrm{R}^{2}=0.9669, \mathrm{~F}$ value=1400.3, $\operatorname{Pr}(\mathrm{T}>\mathrm{t})<0.0001$ & & \\
\hline
\end{tabular}

\subsection{Model Prediction}

The above analysis has answered our proposed three research questions. To use the models in the planning phase, we first calculate the average proportion of each travel time component in total travel time based on figures from Figure 2. The average proportion of walking time, waiting time and in-vehicle time are $23 \%, 17 \%$ and $60 \%$ of average total travel time. Therefore, we can estimate the average perceived travel time at each stage if the average total travel time is given. For example, if the average total travel time is observed around $45 \mathrm{~min}$, then the average actual walking, waiting and in-vehicle time are $10.35 \mathrm{~min}, 8.10 \mathrm{~min}$, and $26.55 \mathrm{~min}$, respectively. Based on Tables 5, 7 and 9, the corresponding perceived walking, waiting and in-vehicle time could be estimated. Figure 3 clearly illustrates the prediction of average perceived walking time, perceived waiting time and perceived in-vehicle time based on the total travel time, in which the total travel time ranges from 20 min to 80 min. The actual travel time distribution is given in Figure 3(a). The basic scenario in Figure 3(b) only considers the influence of actual travel time at each trip stage while the scenario in Figure 3(c) takes the maximum effect from socioeconomic characteristics, trip characteristics and facility usage into account. For the 45 min trip, if the influences from socioeconomic characteristics, trip characteristics and facility usage are not considered, perceived walking, waiting and in-vehicle time will be 11.12 
$\min , 8.55$, and $27.05 \mathrm{~min}$. If the influences from these factors are taken into account, the corresponding maximum travel time perceptions will be $11.55 \mathrm{~min}, 8.70 \mathrm{~min}$, and $27.40 \mathrm{~min}$. The comparison also proves that: the out-of-vehicle travel time is a significant amount in a multimodal public transport trip. The effect of socioeconomic characteristics, trip characteristics and facility usage may increase about $5 \%$ of the overestimation on the perceived travel time. Planner could take effective actions within the system to improve the level of service by reducing the travel time perception.

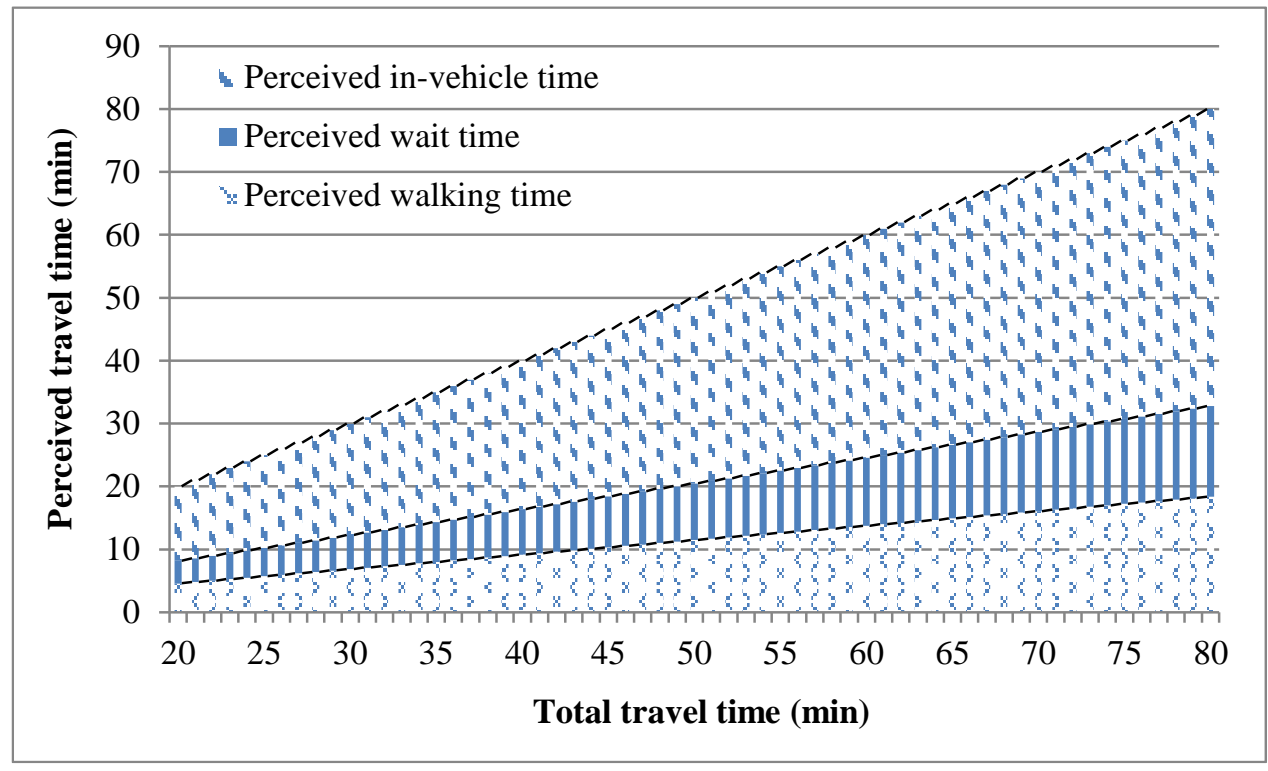

(a) Actual travel time distribution according to the total travel time

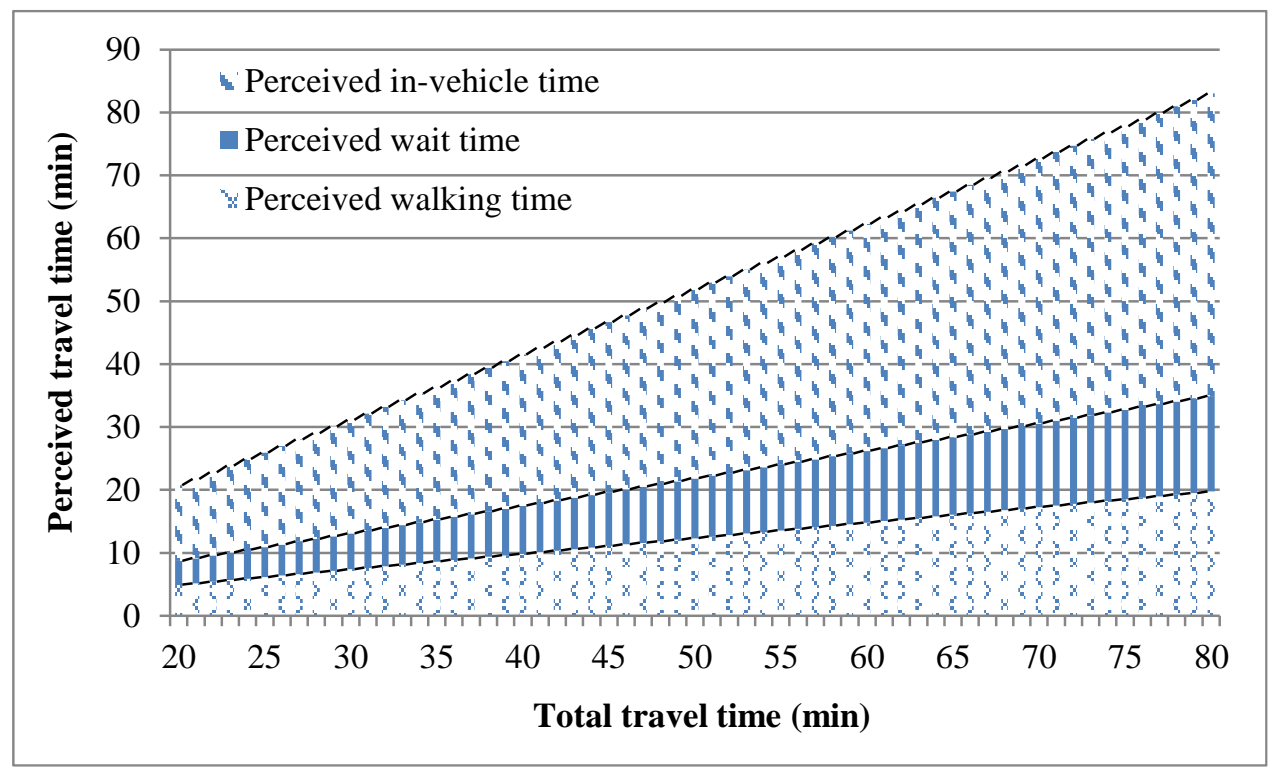

(b) Travel time perception while only the effect from actual travel time is considered 


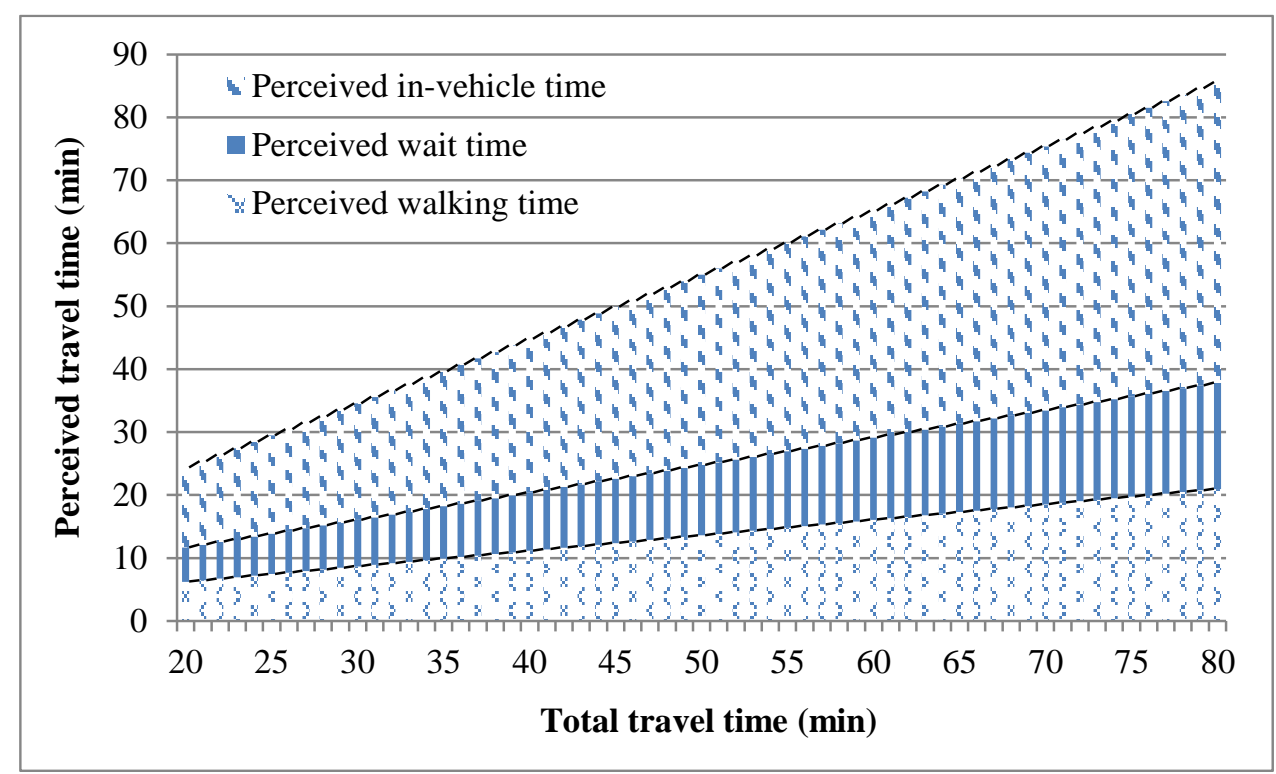

(c) Maximum travel time perception with consideration the effects from socioeconomic characteristics, trip characteristics and facility usage

Figure 4 Actual and perceived travel time based on the total travel time

\section{Conclusion}

The underlying goal of this research is to help transit agencies improve the passengers' stratification on the level of service by investigating the perception travel time in different stages in a bus-rail public transport trip. Based on the data from accompany survey, perception and actual travel time, as well as socioeconomic characteristics and travel characteristics were collected in this study to investigate the influence variables on passengers' perception. A stepwise linear regression method was used to determine the significant variables for the prediction of walking time perception and waiting time perception.

From the results, it could be concluded that passengers do perceive travel time greater than they actually spend at each stage. Actual walking time, travel distance, weather, occupation, trip purpose, covered shelter usage and elevator usage will affect the perception of walking time. Actual waiting time, age and arrival time panel usage will influence the perception of waiting time. Walking time experienced before the current stage will not affect the waiting time perception in the current stage. Actual in-vehicle time and peak hour will affect the perception of in-vehicle travel time.

Compared with the results from previous studies as listed in Table 1, our numbers are much smaller. The reasons may include: (1) Because of the small city-state of Singapore, the average travel 
distance is relatively shorter than other cities. The high frequency transit service also guarantees the passengers to get the service within a short time period. Therefore, the perception differences of all travel time components could be less than other cities. (2) The survey method used in this study is to ask the travel time perception immediately after the each action performed, which may cause the passengers' attention to care the travel time in a subconscious state. Then the reported perceived travel is closer to the actual travel time. From the perspective of impact factors, our results are in line with other studies that socioeconomic characteristics, trip characteristics and facility usage do affect the travel time perception at each trip stage in varying degrees. The insignificance of gender and trip purpose on the perceived waiting time goes against the results from previous studies (Psarros et al. 2011; Cheng and Tsai, 2014; Fan et al., 2016). This may due to different local features and transportation system characteristics. We also find that travel time spent on the previous stage does not affect the perception too much. Further research shall consider the results into public transport values of time studies, mode choice studies, and the influence from other possible factors such as the on-board inspection of tickets.

\section{Acknowledgments}

This study is supported by the Singapore National Research Foundation under its Campus for Research Excellence And Technological Enterprise (CREATE) programme. The authors would like to thank all the student helpers for conducting the accompany survey in this study.

\section{References}

Anderson, M. K., Nielsen, O. A., \& Prato, C. G. (2014). Multimodal route choice models of public transport passengers in the Greater Copenhagen Area. EURO Journal on Transportation and Logistics, $1-25$.

Beirão, G., \& Cabral, J. S. (2007). Understanding attitudes towards public transport and private car: A qualitative study. Transport policy, 14(6), 478-489.

Block, R. A., \& Gruber, R. P. (2014). Time perception, attention, and memory: a selective review. Acta psychologica, 149, 129-133.

Cascetta, E., \& Cartenì, A. (2014). The hedonic value of railways terminals. A quantitative analysis of the impact of stations quality on travellers behaviour. Transportation Research Part A: Policy and Practice, 61, 41-52. 
Chapman, B., Iseki, H., Taylor, B. D., and Miller, M. (2006). The effects of out-of-vehicle time on travel behavior: Implications for transit transfers (Deliverable\# 1). Access from: http://www.its.ucla.edu/wp-content/uploads/sites/6/2014/06/Appendix-A.pdf

Cheng, Y. H., \& Tsai, Y. C. (2014). Train delay and perceived-wait time: passengers' perspective. Transport Reviews, 34(6), 710-729.

Daskalakis, N. G., \& Stathopoulos, A. (2008). Users' perceptive evaluation of bus arrival time deviations in stochastic networks. Journal of Public Transportation, 11(4), 25-38.

Debrezion, G., Pels, E., \& Rietveld, P. (2009). Modelling the joint access mode and railway station choice. Transportation Research Part E: logistics and transportation review, 45(1), 270-283.

Dewulf, B., Neutens, T., Van Dyck, D., De Bourdeaudhuij, I., \& Van de Weghe, N. (2012). Correspondence between objective and perceived walking times to urban destinations: Influence of physical activity, neighbourhood walkability, and socio-demographics. International journal of health geographics, 11(1), 1-10.

Diab, E. I., Badami, M. G., \& El-Geneidy, A. M. (2015). Bus transit service reliability and improvement strategies: Integrating the perspectives of passengers and transit agencies in North America. Transport Reviews, 35(3), 292-328.

Fan, Y., Guthrie, A., \& Levinson, D. (2016). Waiting time perceptions at transit stops and stations: Effects of basic amenities, gender, and security. Transportation Research Part A: Policy and Practice, 88, 251-264.

Fan, W., \& Machemehl, R. (2009). Do transit users just wait for buses or wait with strategies? Some numerical results that transit planners should see. Transportation Research Record: Journal of the Transportation Research Board, (2111), 169-176.

Hall, R. W. (2001). Passenger waiting time and information acquisition using automatic vehicle location for verification. Transportation Planning and Technology, 24(3), 249-269.

Hess, D. B., Brown, J., \& Shoup, D. (2004). Waiting for the bus. Journal of Public Transportation, 7(4), 67-84.

Ji, Y., Zhang, R., Gao, L., \& Fan, Y. (2017). Perception of transfer waiting time at stops and stations in Nanjing, China. Transportation Research Board 96th Annual Meeting, No. 17-01983.

Krygsman, S., Dijst, M., \& Arentze, T. (2004). Multimodal public transport: an analysis of travel time elements and the interconnectivity ratio. Transport Policy, 11(3), 265-275.

Lagune-Reutler, M., Guthrie, A., Fan, Y., \& Levinson, D. (2016). Transit Stop Environments and Waiting Time Perception: Impacts of Trees, Traffic Exposure, and Polluted Air. Transportation Research Record: Journal of the Transportation Research Board, (2543), 82-90.

Meng, M., Koh, P. P., \& Wong, Y. D. (2016). Influence of Socio-Demography and Operating Streetscape on Last-Mile Mode Choice. Journal of Public Transportation, 19(2), 38-54.

Millonig, A., Sleszynski, M., \& Ulm, M. (2012, September). Sitting, waiting, wishing: Waiting time perception in public transport. In Intelligent Transportation Systems (ITSC), 2012 15th International 
IEEE Conference on (pp. 1852-1857). IEEE.

Mishalani, R. G., McCord, M. M., \& Wirtz, J. (2006). Passenger wait time perceptions at bus stops: Empirical results and impact on evaluating real-time bus arrival information. Journal of Public Transportation, 9(2), 89-106.

Nesheli, M. M., Ceder, A. A., \& Estines, S. (2016). Public transport user's perception and decision assessment using tactic-based guidelines. Transport Policy, 49, 125-136.

Parthasarathi, P., Levinson, D., \& Hochmair, H. (2013). Network structure and travel time perception. PloS one, 8(10), e77718.

Psarros, I., Kepaptsoglou, K., \& Karlaftis, M. G. (2011). An empirical investigation of passenger wait time perceptions using hazard-based duration models. Journal of Public Transportation, 14(3), 109-122.

Varotto, S. F., Glerum, A., Stathopoulos, A., Bierlaire, M., \& Longo, G. (2015). Modelling travel time perception in transport mode choices. In 94th Annual Meeting Transportation Research Board, Washington, No. 15-2045.

Vierordt, K. (1868). Der Zeitsinn nach Versuchen. [Empirical studies of time experience],TuĖbingen: H. Laupp.

Walle, S. V., \& Steenberghen, T. (2006). Space and time related determinants of public transport use in trip chains. Transportation Research Part A: Policy and Practice, 40(2), 151-162.

Watkins, K. E., Ferris, B., Borning, A., Rutherford, G. S., \& Layton, D. (2011). Where Is My Bus? Impact of mobile real-time information on the perceived and actual wait time of transit riders. Transportation Research Part A: Policy and Practice, 45(8), 839-848.

Yarmey, A. D. (2000). Retrospective duration estimations for variant and invariant events in field situations. Applied Cognitive Psychology, 14(1), 45-57.

Yoh, A., Iseki, H., Smart, M., \& Taylor, B. (2011). Hate to wait: Effects of wait time on public transit travelers' perceptions. Transportation Research Record: Journal of the Transportation Research Board, (2216), 116-124. 